\title{
Pyrolysis of Waste Plastics Using Catalysts: Activated Carbon, MCM-41 and HZSM-5
}

\author{
Norbert Miskolczi, Chunfei Wu, and Paul T. Williams
}

\begin{abstract}
Waste material was pyrolyzed in a horizontal tubular reactor at $530-540^{\circ} \mathrm{C}$ using different catalysts, such as activated carbon, MCM-41, HZSM-5 and their mixtures. Products were investigated by gas-chromatography, EDXRFS and standardized methods. Catalysts significantly affected the yields of volatiles; e.g. HZSM-5 catalyst increased especially the yield of gaseous hydrocarbons, while MCM-41 catalyst was responsible for increasing the pyrolysis oil yield. Synergistic effects were found using mixtures of different catalysts. Furthermore the catalysts modified the main carbon frame of the products. Pyrolysis oil obtained over HZSM-5 catalyst contained large amounts of aromatics, while MCM-41 catalyst mainly isomerized the carbon frame. Regarding contaminants it was concluded, that the sulphur content could be significantly decreased by activated carbon, however it had only a slight effect to the other properties of the products.
\end{abstract}

Index Terms-Pyrolysis, catalyst, gas-chromatography, utilization.

\section{INTRODUCTION}

Chemical recycling (pyrolysis) is one of the possible ways for efficient waste plastic utilization. The process has benefits not only by reducing the huge mass of polymer wastes, but also enormous energy could be saved by chemical recycling. During pyrolysis, the polymer macromolecules decompose into gaseous and liquid products, which have many similarities with commercial fuel gas, naphtha or even gas oil In general, $400-1000{ }^{\circ} \mathrm{C}$ is used for waste depolymerization depending on the type of reactor (using batch reactor, tubular reactor, fluidized bed, rotary kiln, etc.) [1]-[5]. Higher temperature promotes the formation of gaseous hydrocarbons, coke deposits, and the products contain many cyclic hydrocarbons or aromatics. Aliphatic hydrocarbons (both saturated and unsaturated) are the main products using lower pyrolysis temperatures $\left(<600^{\circ} \mathrm{C}\right)$ [4]-[9]. The product yields and composition are affected also by the application of catalysts, which could increase the yield of volatiles (both gases and pyrolysis oils) [10]-[14]. Besides process advantages, the application of catalysts poses some

Manuscript received November 14, 2015; revised September 12, 2016 This work was supported in part by the Horizon 2020, Marie Curie Research and Innovation Staff Exchange (RISE) (MSCA-RISE-2014 (Flexi-pyrocat, No.: 643322)).

N. Miskolczi is with the Chemical Engineering and Process Engineering Institute, MOL Department of Hydrocarbon and Coal Processing, University of Pannonia, Veszprém, 10 Egyetem u., 8200, Hungary (e-mail: mnorbert@ almos.uni-pannon.hu)

C. Wu is with the School of Engineering, University of Hull, Hull, HU6 7RX, UK (e-mail: c.wu@hull.ac.uk).

P .T. Williams is with the School of Cehemical \& Process Engineering, University of Leeds, Leeds, LS2 9JT, UK (e-mail p.t.williams@leeds.ac.uk) difficulties; e.g., maintaining constant catalyst activity, avoidance of sudden catalyst deactivation, etc. It was demonstrated, that the structure of zeolites had a key role in relation to the product properties. For example, mainly alkanes are produced over y-zeolite, while unsaturated hydrocarbons and aromatics are the main products using ZSM-5 [4], [10], [11], [15].

Worldwide, many different processes are available for waste plastic pyrolysis at least in pilot or industrial scale, but many of them have been temporarily or permanently shut down. The main challenges are the economical return and the guarantee of constant high product quality. Especially the undesired hydrocarbons and contaminants in the products cause serious problems. Based on references, the energetic application of pyrolysis product is the mostly investigated process [16], [17]. However there are different alternatives for further product utilization, depending on the pyrolysis parameters (Fig. 1).

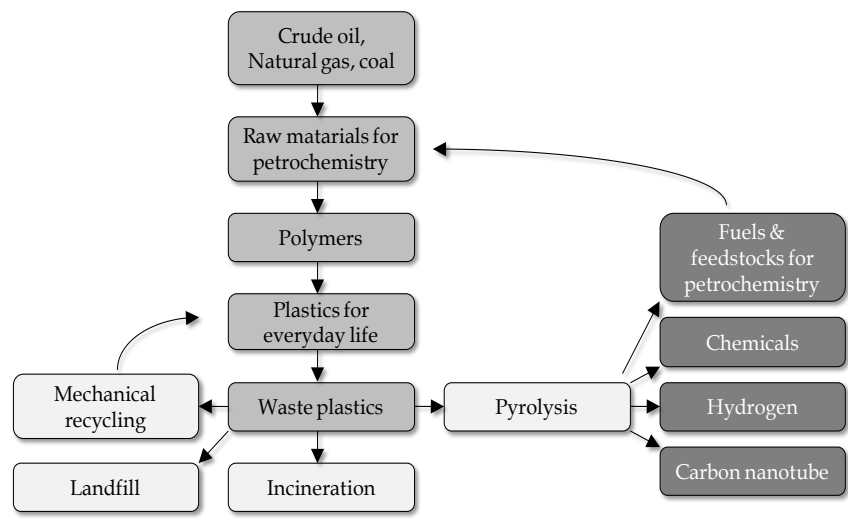

Fig. 1. Ways for utilizations of pyrolysis products obtained by waste plastic

Not only fuels, but also different other valuable products could be generated: chemicals, hydrogen, olefin rich fractions for petrochemical application, carbon nanotube, carbon black, etc. Hydrogen rich gas is the main product, using metal containing catalyst and high temperature, while olefin rich fraction and other chemicals are the main products using catalyst with high $\mathrm{Si} / \mathrm{Al}$ ratio. Carbon nanotube production also requires special catalyst and elevated temperature. It is important to remark that corrosion and emission problems could occur when contaminated pyrolysis products are further used. Therefore the decreasing of contaminants in products is a major problem [9].

In this work thermo-catalytic pyrolysis of waste low density polyethylene and high density polyethylene was investigated in a horizontal tubular reactor at $530-540^{\circ} \mathrm{C}$ using activated carbon, MCM-41 and HZSM-5 catalysts and their mixtures. Especially the effect of catalysts and their mixtures to the product yield and composition was investigated. 


\section{MATERIALS AND METHODS}

\section{A. Raw Materials}

Mixture of real waste high density polyethylene (HDPE) and low density polyethylene (LDPE) obtained from packaging was used in this work. According to preliminary analysis, raw material contained $74.8 \%$ HDPE and $15.2 \%$ LDPE. The main properties of the raw materials are summarized in Table I. Samples with average particle size of 3-4 $\mathrm{mm}$ were used. The real waste raw material is contaminated by chlorine $(0.05 \%)$ and sulfur $(0.02 \%)$, while the moisture and ash content were $1.4 \%$ and $2.9 \%$, respectively.

TABLE I: The MAin PROPERTIEs of ReAl WASTE Plastics

\begin{tabular}{ll}
\hline \hline Property & Value \\
\hline Average particle size, $\mathrm{mm}$ & $3-4$ \\
Proximate analysis & \\
$\quad$ Ash content, $\%$ & 2.9 \\
Volatile content, \% & 1.4 \\
Combustible, $\%$ & 95.7 \\
Ultimate analysis & \\
$\mathrm{C}, \%$ & 85.71 \\
$\mathrm{H}, \%$ & 14.21 \\
$\mathrm{Cl}, \%$ & 0.05 \\
$\mathrm{~S}, \%$ & 0.02 \\
\hline \hline
\end{tabular}

In order to modify the yield and composition of products, different catalysts and their mixtures were tested: activated carbon, MCM-41 and HZSM-5. Table II demonstrates the composition of catalyst mixtures.

TABLE II: THE COMPOSITION OF CATALYSTS (IN W/W\%)

\begin{tabular}{llll}
\hline \hline Catalyst & Activated carbon & MCM-41 & HZSM-5 \\
\hline C-1 & 100 & - & - \\
C-2 & - & 100 & - \\
C-3 & - & - & 100 \\
C-4 & 50 & 50 & - \\
C-5 & 50 & - & 50 \\
C-6 & - & 50 & 50 \\
C-7 & 33.33 & 33.33 & 33.33 \\
\hline \hline
\end{tabular}

The main properties of the catalysts are summarized in Table III. Catalysts have similar grain size, in the range between 10 and $109 \mu \mathrm{m}$. MCM-41 has lower acidity than HZSM-5. Activated carbon and MCM-41 catalyst shows the highest BET surface area with $859 \mathrm{~m}^{2} \mathrm{~g}^{-1}$ and $824 \mathrm{~m}^{2} \mathrm{~g}^{-1}$, respectively.

TABLE III: THE PROPERTIES OF CATALYSTS

\begin{tabular}{llll}
\multicolumn{4}{c}{ TABLE III: THE PROPERTIES OF CATALYSTS } \\
\hline & $\begin{array}{l}\text { Activated } \\
\text { carbon }\end{array}$ & MCM-41 & HZSM-5 \\
\hline $\begin{array}{l}\text { Grain size, } \mu \mathrm{m} \\
\text { Si/Al ratio }\end{array}$ & $10-109$ & $15-84$ & $10-79$ \\
$\begin{array}{l}\text { Acidity, mequiv of } \\
\mathrm{NH}_{3} / \mathrm{g}\end{array}$ & - & - & 25 \\
$\mathrm{BET}$ area, $\mathrm{m}^{2} / \mathrm{g}$ & - & 0.15 & 0.60 \\
\hline \hline
\end{tabular}

\section{B. Apparatus for Waste Plastic Pyrolysis}

A horizontal tubular reactor was used for waste plastic pyrolysis. Fig. 2 demonstrates the pyrolysis apparatus. A hopper was filled with the plastic in the first section of the electrically heated extruder. The feed rate was $2 \mathrm{~kg}$ hourly. The molten waste raw material was directly fed into the reactor stage from the extruder end section, where it was quickly heated to $530-540^{\circ} \mathrm{C}$. Waste HDPE and LDPE were decomposed into smaller hydrocarbon molecules in the reactor. The mixtures of decomposed hydrocarbons were separated into gases, pyrolysis oil and heavy oil in a distillation column connected to the end section of the reactor. Gases from the top section of the distillation column were condensed in a water cooled tubular heat exchanger, and then a given ratio of the condensed product (pyrolysis oil) was driven back to the distillation unit top section. Higher efficiency of distillation could be reached by this procedure. The bottom temperature of the separation unit was between 300 and $350^{\circ} \mathrm{C}$. The bottom products were separated into two fractions by hot press filtration: heavy oil and solid char. Temperature of $120^{\circ} \mathrm{C}$ and pressure of 1.5 barg were used during the filtration. Temperatures were controlled by PID controllers in all of the experiments. In case of thermo-catalytic pyrolysis, $4 \mathrm{wt} \%$ of catalyst in relation to the weight of the raw material was added. Products were collected and further analyzed.

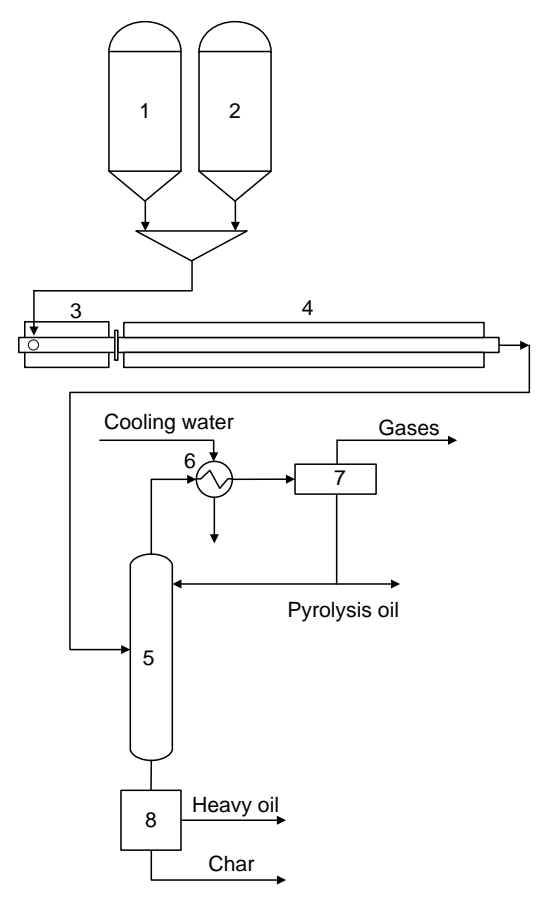

Fig. 2. Continuous pyrolysis apparatus (1-waste silo, 2-catalyst storage, 3-extruder, 4-reactor, 5-sepration column, 6-cooler, 7-separator, 8-hot press filter).

\section{Methods}

Gases and pyrolysis oil were analyzed by DANI gas-chromatograph coupled with flame ionization detector (FID). For gas analysis, a $50 \mathrm{~m} \times 0.32 \mathrm{~mm}$ fused silica column with $\mathrm{Al}_{2} \mathrm{O}_{3} / \mathrm{KCl}$ coating was used and the temperature was constant at $40^{\circ} \mathrm{C}$ during the analysis. In the case of pyrolysis oil analysis, a $30 \mathrm{~m} \times 0.32 \mathrm{~mm}$ Rtx ${ }^{\circledR}-1$ column was used. The temperature was elevated from $40^{\circ} \mathrm{C}$ to $330{ }^{\circ} \mathrm{C}$ with $15^{\circ} \mathrm{C} \mathrm{min}^{-1}$ ramp, and then the temperature was kept constant for 10 minutes. 
The concentrations of sulphur and chlorine were measured by a PHILLIPS PW 4025/02 (MiniPal) EDXRF spectrometer, which was fitted with a rhodium-side window tube anode (power of 9W) and Si-PIN detector.

Volatile characteristic of pyrolysis oil was also determined by Engler distillation test to measure the volume of hydrocarbon distilled at given temperatures (ASTM-D 1078).

The structure of heavy oils was investigated by a TENSOR 27 FTIR spectrometer (resolution: $2 \mathrm{~cm}^{-1}$, illumination: $\mathrm{SiC}$ Globar light, monocromator: Littrow prism, detector: RT-DLaTGS (Deutero L- $\alpha$-Alanine Triglycin-Sulphate) type detector with $\mathrm{KBr}$ window) in the $4000-400 \mathrm{~cm}^{-1}$ wave number ranges.

The unsaturated content of pyrolysis oils were analyzed by the determination of iodine-bromine number according to ASTM-D 149-60.

The filtered heavy oil fractions were analyzed by the following methods: flash point determination (ISO 2719:2002 and MSZ 15967:1979), determination viscosity (MSZ ISO 3105:1998), melting point determination (MSZ 3252:1973), density measurement (MSZ EN 1285:1996), and heating value (MSZ 24000-5:1978).

\section{RESULTS AND DisCUSSION}

\section{A. Product Yields}

Product yields are summarized in Fig. 3, which shows significant differences among quantities of gases, pyrolysis oil and heavy oil in the presence of catalysts and their mixtures.

Pyrolysis of waste polymers resulted in $42.7 \%$ pyrolysis oil and $5.1 \%$ gases without catalyst. Oil and gas yields changed slightly using activated carbon, as the yields of gases and pyrolysis oil were only increased to $7.2 \%$ and $49.2 \%$, respectively. The slight increase of the yields of gas and oil could be attributed to the larger heat transmission area, which was due to the high BET surface area of the activated carbon.

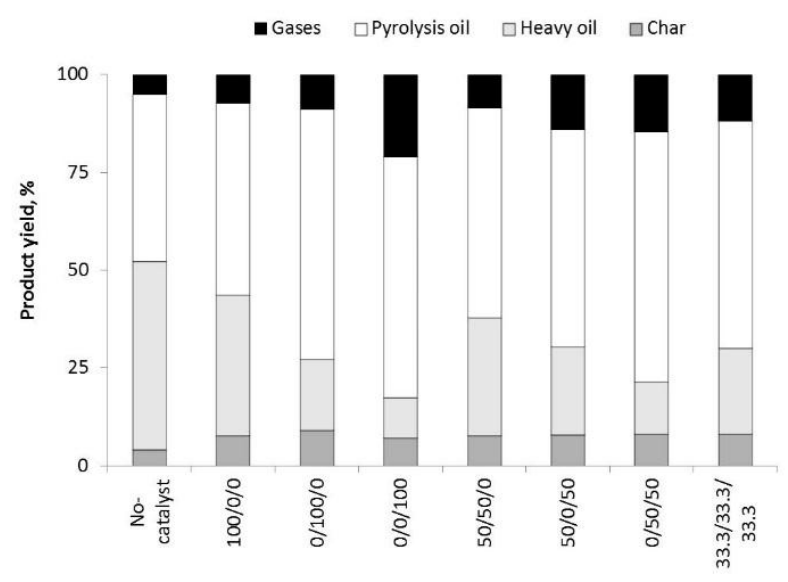

Fig. 3. Product yields using different catalysts.

The increase of gas and oil production was well shown using MCM-41 or HZSM-5 catalysts. The HZSM-5 significantly increased the yield of gaseous production to $21.1 \%$, while $63.9 \%$ and $61.4 \%$ pyrolysis oil yield was observed using the MCM-41 and HZSM-5 catalysts, respectively. Regarding the use of mixed catalysts, it is indicated that the addition of the activated carbon only slightly deteriorated the advantageous properties of both the MCM-41 and HZSM-5 in terms of oil production. Furthermore nearly the highest $(63.7 \%)$ yield of pyrolysis oil was obtained from waste pyrolysis over $50 \% / 50 \%$ MCM-41/HZSM-5 catalysts. The MCM-41 catalyst had larger pore size than the HZSM-5; therefore it has higher catalytic activity for producing oils with comparative large molecules, while the HZSM-5 catalyst with smaller pores promoted the production of small-molecule gaseous products. The yield of solid char was between $4.1 \%$ and $9.2 \%$. The lowest char amount was found without catalyst, while the MCM-41 catalyst resulted the highest yield of solid char. The high amount of solid char on catalyst surface resulted from the high catalytic activity of the MCM-41 catalyst in cracking reactions.

\section{B. Gases}

The compositions of gaseous products are summarized in Tables IV/A and IV/B. Based on GC analysis, it is clear that the gaseous fraction contains methane, ethane and ethene, propene and propane, butane and butene, iso- $\mathrm{C} 4$, pentene and pentane, iso-C5 hydrocarbons.

TABLE IV/A: Composition of Gases ObTaIned By Waste Plastic PYROLYSIS AT $530-540^{\circ} \mathrm{C}$, IN VOL $\%$

\begin{tabular}{lrrrr}
\hline \hline Catalyst & No-catalyst & C-1 & C-2 & C-3 \\
\hline Methane & 13.5 & 16.9 & 14.3 & 22.3 \\
Ethene, Ethane & 26.9 & 25.6 & 21.7 & 17.0 \\
Propene, Propane & 22.8 & 20.7 & 22.8 & 15.0 \\
Butene, Butane & 28.6 & 28.4 & 18.2 & 18.8 \\
iso-C4 & 3.4 & 2.8 & 11.7 & 16.6 \\
Pentene, Pentane & 4.0 & 4.2 & 5.1 & 4.3 \\
iso-C5 & 0.9 & 1.5 & 6.3 & 6.0 \\
\hline \hline
\end{tabular}

From Table IV, it is demonstrated that the majority gases are $\mathrm{C}_{2}, \mathrm{C}_{3}$ and $\mathrm{C}_{4}$ hydrocarbons in the absence of catalyst. Similar results were found in the presence of catalysts; however notable isomerisation of the main carbon frame was also demonstrated (Table IV). Especially the iso-C4 concentration was increased with the addition of catalyst; it was $11.7 \%$ and $16.6 \%$ using the MCM-41 and HZSM-5 catalyst, respectively. It is important to remark that the application of activated carbon did not affect significantly the concentration of gaseous components.

\begin{tabular}{|c|c|c|c|c|}
\hline Catalyst & $\mathrm{C}-4$ & $\mathrm{C}-5$ & $\mathrm{C}-6$ & $\mathrm{C}-7$ \\
\hline Methane & 13.6 & 19.8 & 16.1 & 13.7 \\
\hline Ethene, Ethane & 20.8 & 21.0 & 19.6 & 23.1 \\
\hline Propene, Propane & 19.6 & 16.4 & 20.6 & 21.3 \\
\hline Butene, Butane & 25.6 & 21.0 & 18.8 & 17.0 \\
\hline iso-C4 & 11.1 & 15.4 & 13.8 & 13.0 \\
\hline Pentene, Pentane & 3.8 & 3.7 & 4.9 & 6.3 \\
\hline iso-C5 & 5.5 & 2.7 & 6.2 & 5.6 \\
\hline
\end{tabular}

Regarding the catalysts mixtures, it is suggested that slight influences were observed when the activated carbon was added to the MCM-41 or the HZSM-5, in terms of the concentration of gas components. For example, the iso-C4 content was $11.1 \%$ and $15.4 \%$ over $50 \%$ activated carbon and 
$50 \%$ MCM-41, or 50\% activated carbon and 50\% HZSM-5, respectively. The concentration of iso-C5 compounds was increased from $0.9 \%$ (without catalyst) to $1.5 \%$ (activated carbon) and further to $6.3 \%$ (MCM-41). Regarding the gaseous fraction, the HZSM-5 catalyst had a more significant isomerisation effect than the MCM-41 catalyst, which could be attributed to its higher BET area (Table III). The main frame of instable molecule fragments could be isomerized in the propagation reaction step resulting in high concentrations of branched molecules.

\section{Pyrolysis Oil}

Pyrolysis oils were analyzed by gas-chromatography to determine the oil composition. It is indicated that $\mathrm{C}_{5}-\mathrm{C}_{34}$ hydrocarbons were presented in the pyrolysis oils. The composition of pyrolysis oils as a function of carbon atoms are shown in Fig. 4. Owing to the structure of HDPE and LDPE, two well separated peaks appeared around C9 and C15, respectively.

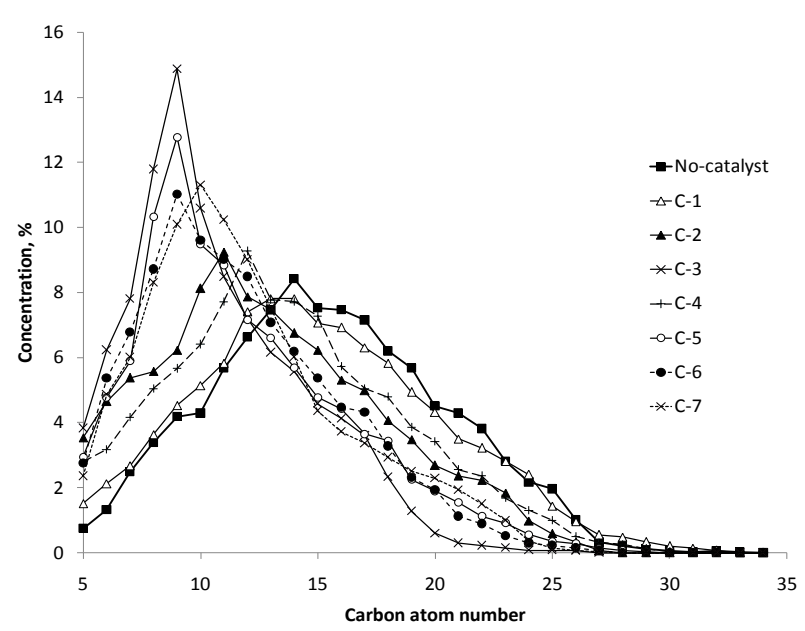

Fig. 4. Distribution of compounds in pyrolysis oil as function of carbon atoms.

Regarding the thermal pyrolysis without catalyst, compounds with carbon atoms of 14 had the highest concentration $(8.43 \%)$. The introduction of the activated carbon changed slightly the distribution curve, because the maximum compound concentration (7.82\%)) is obtained at carbon atoms of 14, which is similar to the experiment without catalyst. However both the MCM-41 and HZSM-5 catalysts had a significant effect on the product distribution. For example, the maximum points were shifted to carbon atoms of $11(9.02 \%)$ and $9(14.88 \%)$ using the MCM-41 and the HZSM-5 catalysts, respectively.

Significant increases of oil compounds with shorter chain $\left(<\mathrm{C}_{14}\right)$ were found using the MCM-41 and HZSM-5 catalysts, while the concentration of larger molecules $\left(>\mathrm{C}_{14}\right)$ decreased. It is suggested that the average molecular weight was decreased using both the MCM-41 and HZSM-5 catalysts (Fig. 5). For example, it is shown that the average molecular weight of pyrolysis oil was $242 \mathrm{~g} \mathrm{~mol}^{-1}$ without catalyst. The average molecule weight was significantly decreased using the MCM-41 (178g mol $\left.{ }^{-1}\right)$ and the HZSM-5 (139g mol $\left.{ }^{-1}\right)$ catalysts, while it could be only slightly decreased by the application of the activated carbon $\left(235 \mathrm{~g} \mathrm{~mol}^{-1}\right)$. Regarding the mixtures of catalysts, the 50\%/50\% HZSM-5 and activated carbon mixture have shown a significant effect resulting in a clear decrease of average molecular weight $\left(142 \mathrm{~g} \mathrm{~mol}^{-1}\right)$.

Fig. 6 shows the composition of pyrolysis oils, which contain non-branched, branched alkanes and aromatic hydrocarbons. It is suggested that catalyst has shown significant effect on the reactions of isomerisation and aromatization. For example, pyrolysis oil contained $89.2 \%$ non-branched and $10.8 \%$ branched hydrocarbons without catalyst. The concentration of branched hydrocarbon increased to $31.9 \%$ and $35.5 \%$ in the presence of the MCM-41 and the HZSM-5 catalysts, respectively.

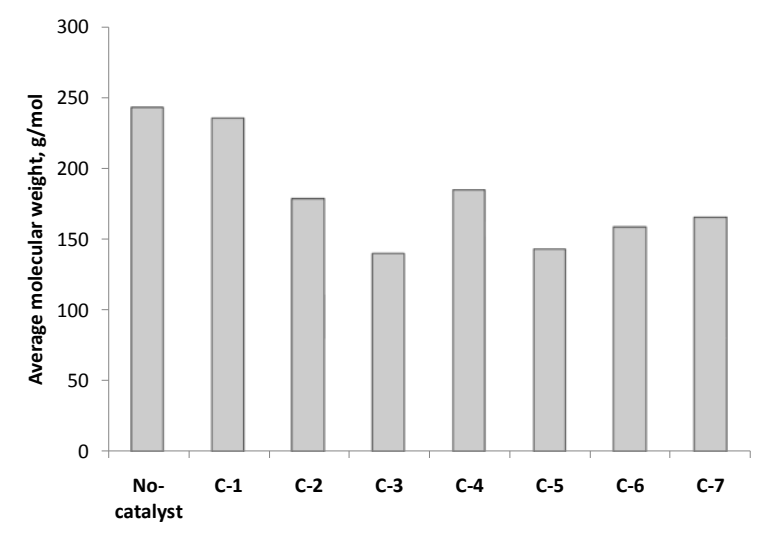

Fig. 5. Calculated average molecular weights of pyrolysis oil.

Regarding aromatics, the HZSM-5 catalyst showed the highest activity, because the concentration of aromatic hydrocarbons reached $34.1 \%$ using the HZSM-5. This result was consistent with earlier work, when the high activity of HZSM-5 catalyst to the aromatization reactions was reported [4], [10], [11], [16].

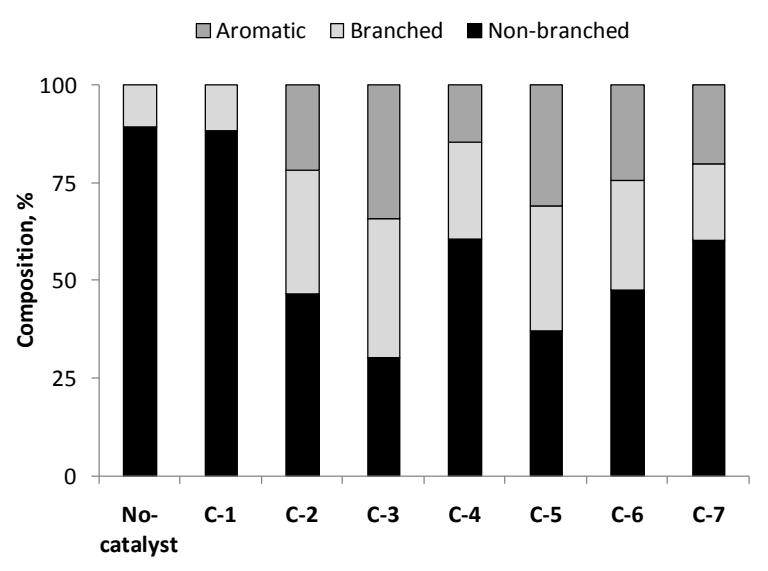

Fig. 6. Composition of pyrolysis oils.

It is also clear, that the activated carbon could not increase the aromatic content in pyrolysis oil. The MCM-41 catalyst showed obvious effect on the isomerisation reactions, which resulted in an elevated concentrations of branched compounds. Regarding the application of catalyst mixtures, the enhancement of aromatization and isomerisation was found in the presence of the HZSM-5 catalyst.

The compositions of aromatics in pyrolysis oils are summarized in Fig. 7. Pyrolysis oils contain benzene, toluene, ethyl-benzene, styrene, xylenes, isopropyl-benzene, a-methyl styrene, cumene and other aromatic hydrocarbons. It is shown that the HZSM-5 catalyst (C-3) resulted in significant 


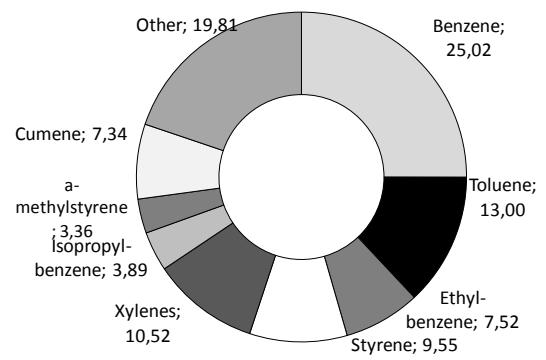

C-3

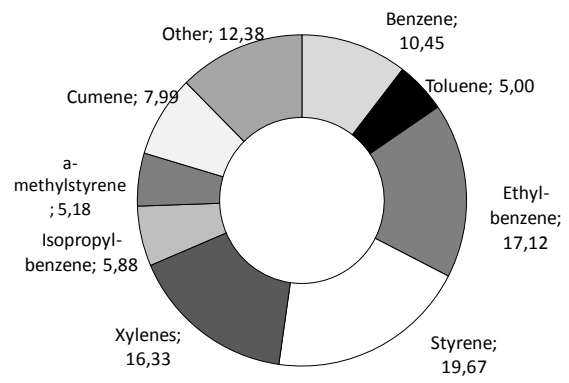

C-4

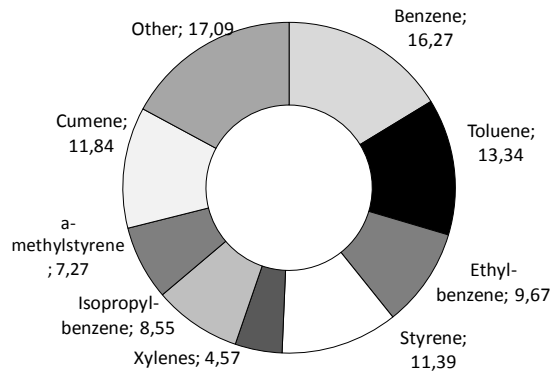

C-5

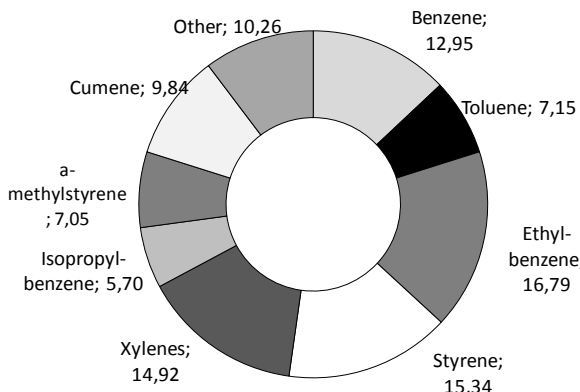

C-6

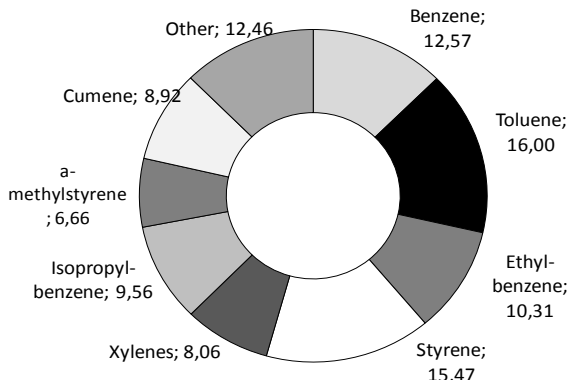

C-7

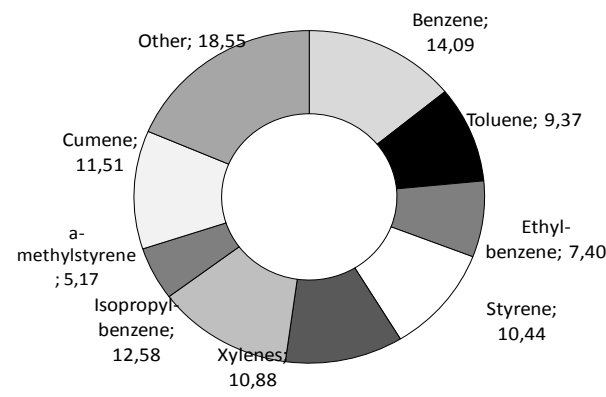

Fig. 7. Composition of aromatics in pyrolysis oils. values of ethyl-benzene, styrene and xylenes were measured; $17.12 \%, 19.67 \%$ and $16.33 \%$, respectively. The MCM-41 catalyst (C-2) has also shown aromatization function; because the total aromatic concentration was increased to $21.6 \%$ using the MCM-41 catalyst.

It is an important observation, that the MCM-41 catalyst showed higher concentrations of benzene and toluene $(25.05 \%$ and $13.00 \%$ ), while that of ethyl-benzene, styrene and xylenes were lower $(7.52 \%, 9.55 \%$ and $10.52 \%)$. This phenomenon could be attributed to the larger pore size and BET surface area of the MCM-41 catalyst, because those properties are favoured for the hydrogen transfer reactions and aromatization. Therefore, the aromatic side chain of aromatics could be further cracked which resulted in smaller molecules with shorter side chain. In addition, the further decomposition of side chain of aromatics were found in the case of catalyst mixtures containing MCM-41 catalyst (C-4, C-6).

As it was demonstrated in Table I, the raw material contained $0.05 \%$ chlorine and $0.02 \%$ sulphur, which could be transformed into compounds, which appeared in the pyrolysis oil fractions. Fig. 8 demonstrates the concentrations of chlorine and sulphur in the pyrolysis oils. Without catalysts, $257 \mathrm{ppm}$ chlorine and $125 \mathrm{ppm}$ sulphur were measured, which could be decreased using catalysts. Regarding chlorine, the MCM-41 catalyst had the highest activity in decreasing the concentrating of $\mathrm{Cl}$ in the oil (122 ppm). The activated carbon showed only a slight effect to the yields and compositions of gas and oil; however it demonstrated a significant effect on sulphur content. Pyrolysis oil obtained by the degradation over the activated carbon contained only $31 \mathrm{ppm}$ sulphur, which is a significant decrease. The two other catalysts only slightly decreased the S content; $79 \mathrm{ppm}$ and $81 \mathrm{ppm}$ using the MCM-41 and the HZSM-5 catalysts, respectively. It is suggested that the large BET surface area was the cause for both $\mathrm{Cl}$ and $\mathrm{S}$ decreases using the MCM-41 and the activated carbon. According to Table I, the activated carbon had $859 \mathrm{~m}^{2} \mathrm{~g}^{-1}$, while the MCM-41 catalyst $824 \mathrm{~m}^{2} \mathrm{~g}^{-1}$ BET surface area. Therefore physical sorption might be ascribed for both $\mathrm{Cl}$ and $\mathrm{S}$ decreasing using the MCM-41 or the activated carbon.

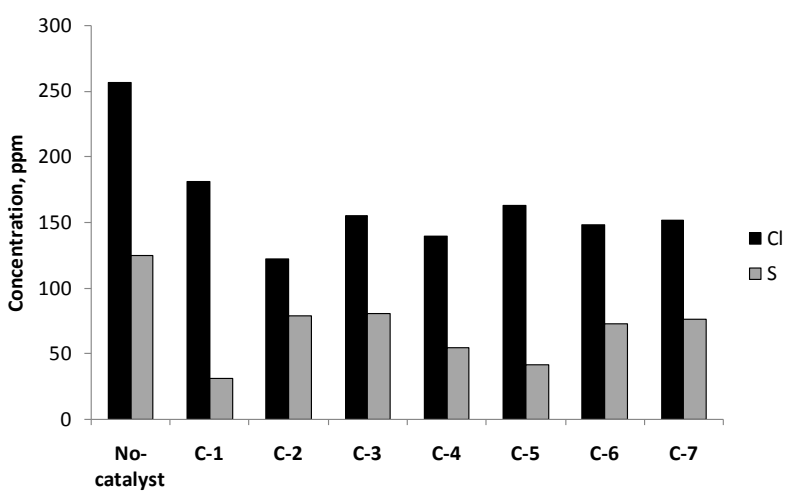

Fig. 8. Chlorine and sulphur content of pyrolysis oils.

Volatile characteristic of pyrolysis oils was also analyzed by Engler distillation test. Fig. 9 summarizes the distillation curves. It is demonstrated that the pyrolysis oil obtained without catalyst contains nearly half of diesel oil range and $25 \%-25 \%$ kerosene and naphtha range hydrocarbons. In the 
presence of catalysts (especially the HZSM-5), the fractions of naphtha-like and kerosene-like hydrocarbons were increased. For example, using the HZSM-5 catalyst, both concentrations of naphtha- and kerosene-like hydrocarbons were nearly $60 \%$ and $25 \%$, respectively. It is supported by earlier work, where HZSM-5 catalyst with small pore size resulted in the production of hydrocarbons in naphtha boiling point range $\left(\mathrm{Bp}\right.$ below $\left.180^{\circ} \mathrm{C}\right)$ [10], [11], [16].

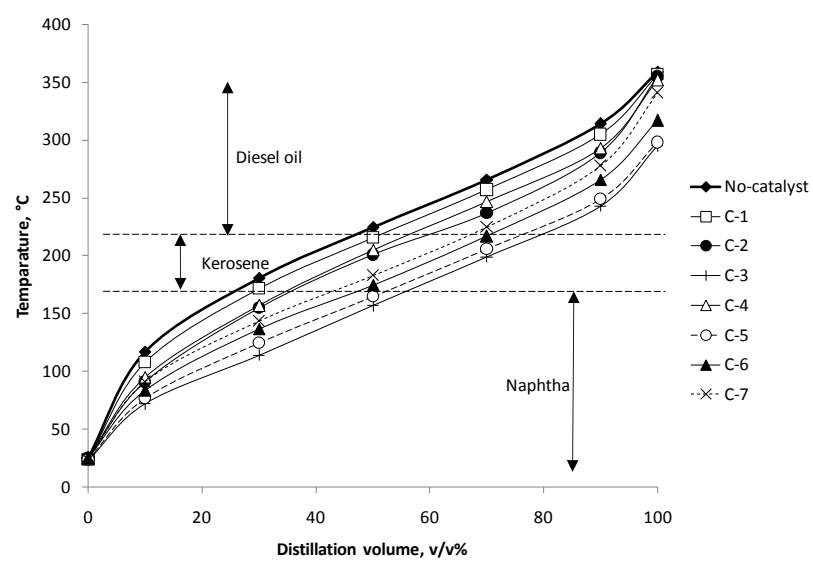

Fig. 9. Engler distillation curves of pyrolysis oils.

The activated carbon had only shown a slight effect on the boiling point range of the pyrolysis oil (Fig. 9). The MCM-41 catalyst also showed slightly affect on the boiling points of oils, although it has notable effect compared to the activated carbon. Regarding catalyst mixtures, it was found that the HZSM-5 containing mixtures (C-5, C-6 and C-7) could significantly increase the yield of naphtha- or kerosene- like compounds and decrease the yield of diesel oil.

Fig. 10 shows the iodine-bromine numbers of pyrolysis oils. The iodine-bromine number refers to the unsaturated content of pyrolysis oils. The iodine-bromine number is proportional to the content of olefins in the pyrolysis oil. It is important to remark, that the iodine-bromine number refers to the unsaturated content of $100 \mathrm{~g}$ product, therefore the average molecular weight of pyrolysis oils could also affect the value of iodine-bromine number.

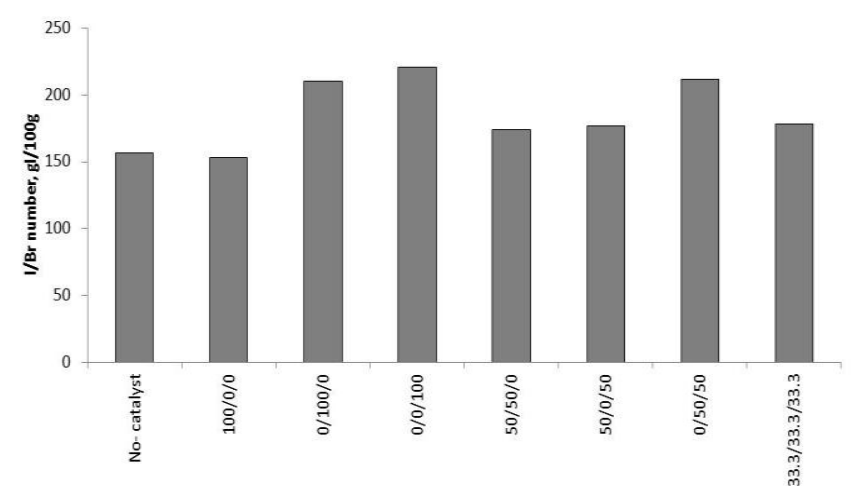

Fig. 10. Iodine-bromine numbers of pyrolysis oils.

Pyrolysis oil obtained by catalyst free experiment has $157 \mathrm{gI} / 100 \mathrm{~g}$ iodine-bromine number, which was not significantly changed using the activated carbon $(153 \mathrm{gI} / 100 \mathrm{~g})$. Higher iodine-bromine number was obtained with the HZSM-5 (221gI/100g) or the MCM-41 (210gI/100g) catalysts. It is suggested that the increased content unsaturated hydrocarbons was the consequence of the promoted cracking reactions. It is known that cracking reactions are taken place by b-scission, which results in the production of olefins, especially in terminal positions. Additionally, MCM-41 and HZSM-5 catalysts are typical cracking catalysts.

\section{Heavy Oil and Char}

The char was separated from the bottom product of the pyrolysis process by hot press filtration into heavy oil and char. The main properties (density, melting point, flash point, viscosity and contaminants) of the heavy oils are summarized in Tables V/A and V/B. According to the results, the density of heavy oil fractions was between 0.81 and $0.85 \mathrm{~g} \mathrm{~cm}^{-3}$, depending on the addition of catalyst and the type of catalyst. The density of heavy oil was the highest from the experiment without catalyst, while the lowest heavy oil density was obtained using the MCM-41 catalyst. Similar tendency was found regarding melting point, flash point and viscosity. The melting point was $84^{\circ} \mathrm{C}$ without catalyst, which was decreased to $74^{\circ} \mathrm{C}$ and $75^{\circ} \mathrm{C}$ using the MCM-41 and the HZSM-5 catalysts, respectively. In general, higher flash point refers to lower volatiles in the oil fraction. The flash point of the heavy oil produced without catalyst was $253^{\circ} \mathrm{C}$, which was only slightly decreased using catalysts $\left(247-250^{\circ} \mathrm{C}\right)$.

TABLE V/A: PROPERTIES OF HEAVY OILS

\begin{tabular}{lrrrr}
\hline \hline & No-catalyst & C-1 & C-2 & C-3 \\
\hline Density at $25^{\circ} \mathrm{C}, \mathrm{g}$ & 0.85 & 0.84 & 0.81 & 0.82 \\
$\mathrm{~cm}^{-3}$ & 84 & 81 & 74 & 75 \\
Melting point, $^{\circ} \mathrm{C}$ & 253 & 251 & 250 & 248 \\
Flash point, ${ }^{\circ} \mathrm{C}$ & & & & \\
Viscosity at $^{2}$ & 6.4 & 6.8 & 7.9 & 8.0 \\
$100^{\circ} \mathrm{C}, \mathrm{mm}^{2} \mathrm{~s}^{-1}$ & & & & \\
Heating value, $_{\text {MJ kg }}^{-1}$ & 41.4 & 40.9 & 41.8 & 41.1 \\
$\mathrm{~S}, \mathrm{ppm}_{\mathrm{Cl}, \mathrm{ppm}}$ & 83 & 16 & 52 & 66 \\
\hline \hline
\end{tabular}

Regarding the kinematic viscosity of heavy oil, it was between 6.8 and $8.0 \mathrm{~mm}^{2} \mathrm{~s}^{-1}$ in the case of thermos-catalytic pyrolysis. However it was $6.4 \mathrm{~mm}^{2} \mathrm{~s}^{-1}$ without catalyst (thermal pyrolysis).

TABLE V/B: PROPERTIES OF HEAVY OILS (CONT.)

\begin{tabular}{lrrrr}
\hline \hline & C-4 & C-5 & C-6 & C-7 \\
\hline Density at $25^{\circ} \mathrm{C}, \mathrm{g}$ & & & & \\
$\mathrm{cm}^{-3}$ & 0.83 & 0.83 & 0.84 & 0.82 \\
Melting point, ${ }^{\circ} \mathrm{C}$ & 77 & 78 & 77 & 76 \\
Flash point, ${ }^{\circ} \mathrm{C}$ & 250 & 247 & 250 & 249 \\
Viscosity at & & & & \\
$100^{\circ} \mathrm{C}, \mathrm{mm}^{2} \mathrm{~s}^{-1}$ & 7.6 & 7.9 & 7.4 & 7.4 \\
Heating value, $^{-1}$ & & & & \\
$\mathrm{MJ} \mathrm{kg}$ & 41.0 & 41.6 & 41.3 & 40.9 \\
$\mathrm{~S}, \mathrm{ppm}$ & 58 & 61 & 45 & 52 \\
$\mathrm{Cl}, \mathrm{ppm}$ & 25 & 28 & 22 & 24 \\
\hline \hline
\end{tabular}

The heating value of heavy oils is a key parameter for their further energetic utilization. In general, high heating value of the fraction is preferred for further utilisation. The heating value of the heavy oils was between 40.9 and $41.6 \mathrm{MJ}$ $\mathrm{kg}^{-1}$, which only slightly changed using different catalysts. 
Sulphur and chlorine could be also detected in the heavy oils. Their concentrations were measured by EDXRFS method. It was found that the heavy oil obtained by catalyst free thermal pyrolysis had 83 and $27 \mathrm{ppm}$ sulphur and chlorine, respectively. Those could be further decreased by catalysts, especially by the activated carbon in case of sulphur reduction. It is also shown that the chlorine concentration in heavy oils was only slightly affected by changing pyrolysis conditions in terms of the addition of catalyst.

Fig. 11 summarizes the composition of heavy oils. It was determined using FTIR analysis. Heavy oils contained aromatic, saturated and unsaturated hydrocarbons. Heavy oils from the pyrolysis of plastic without catalyst and thermo-catalytic pyrolysis over the activated carbon contained only saturated and unsaturated hydrocarbons. However aromatics was measured in the heavy oils produced using the MCM-41 and HZSM-5 catalysts.

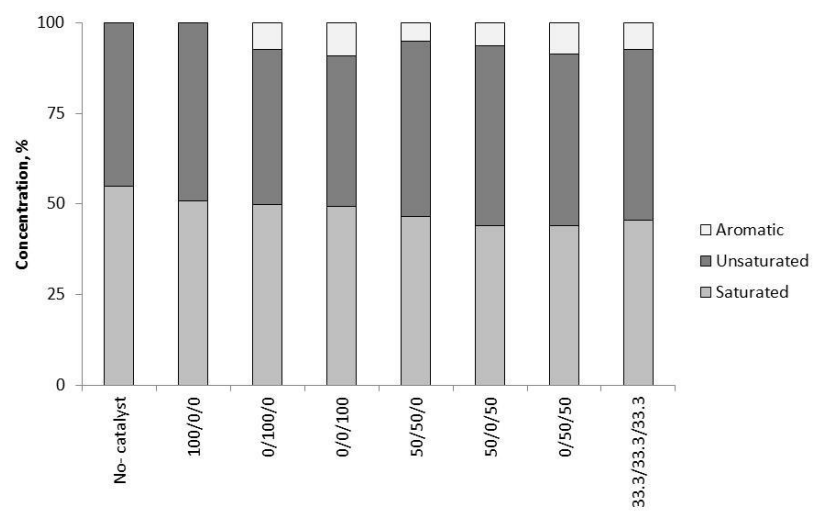

Fig. 11. Composition of heavy oils.

The aromatic concentration was between $5.1 \%$ and $9.2 \%$. The HZSM-5 catalyst had the more significant effect on the aromatic concentration compared to the MCM-41 catalyst. Comparing the compositions of heavy oil and pyrolysis oil, it is shown that the heavy oils had lower concentrations of aromatics.

\section{CONCLUSION}

The yield of gaseous product was increased significantly by the addition of HZSM-5 catalyst, while the yield of pyrolysis oil was increased both by the HZSM-5 and MCM-41 catalysts. Activated carbon had only a slight effect on the yields of gas and oils. Significant isomerization effect was demonstrated using the HZSM-5 catalyst alone or HZSM-5 catalyst containing catalyst mixtures. The MCM-41 and HZSM-5 catalyst had also shown an aromatization effect. The MCM-41 catalyst with larger pore size and activity promoted the formations of benzene and toluene. The most benefit of using the activated carbon was the largely decrease of sulphur content in the pyrolysis oil, while the chlorine content in the pyrolysis oil could be decreased especially by the MCM-41 catalyst, which was attributed to its large surface area. Volatile characteristic analysis of pyrolysis oils demonstrated that the increase of the naphtha-like fraction of pyrolysis oil was observed using the HZSM-5 catalyst.

\section{ACKNOWLEDGMENT}

The authors acknowledge the Horizon 2020, Marie Curie
Research and Innovation Staff Exchange (RISE) (MSCA-RISE-2014 (FLEXI-PYROCAT, No.: 643322)).

\section{REFERENCES}

[1] H. T. Lin, M. S. Huang, J. W. Luo, L. H. Lin, C. M. Lee, and K. L. Ou, "Hydrocarbon fuels produced by catalytic pyrolysis of hospital plastic wastes in a fluidizing cracking process," Fuel Processing Technology, vol. 91 , no. 11, pp. 1355-1363, November 2010.

[2] E. V. Antonakou, K. G. Kalogiannis, S. D. Stefanidis, S. A. Karakoulia, K. S. Triantafyllidis, A. A. Lappas, and D. S. Achilias, "Catalytic and thermal pyrolysis of polycarbonate in a fixed-bed reactor: The effect of catalysts on products yields and composition," Polymer Degradation and Stability, vol. 110, pp. 482-491, December 2014.

[3] Y. H. Lin and M. H. Yang, "Catalytic reactions of post-consumer polymer waste over fluidised cracking catalysts for producing hydrocarbons," Journal of Molecular Catalysis A: Chemical, vol. 231, no. 1-2, pp. 113-122, April 2005.

[4] G. Elordi, M. Olazar, M. Artetxe, P. Castano, and J. Bilbao, "Effect of the acidity of the HZSM-5 zeolite catalyst on the cracking of high density polyethylene in a conical spouted bed reactor," Applied Catalysis A: General, vol. 415-416, pp. 89-95, February 2012

[5] Y. H. Lin and H. Y. Yen "Fluidised bed pyrolysis of polypropylene over cracking catalysts for producing hydrocarbons," Polymer Degradation and Stability, vol. 89, no. 1, pp. 101-108, July 2005.

[6] W. C. Huang, M. S. Huang, C. F. Huang, C. C. Chen, and K. L. Ou, "Thermochemical conversion of polymer wastes into hydrocarbon fuels over various fluidizing cracking catalysts," Fuel, vol. 89, no. 9, pp. 2305-2316, September 2010.

[7] S. S. Kima and S. Kim, "Pyrolysis characteristics of polystyrene and polypropylene in a stirred batch reactor," Chemical Engineering Journal, vol. 98, no. 1-2, pp. 53-60, March 2004.

[8] N. S. Akpanudoh, K. Gobin, and G. Manos, "Catalytic degradation of plastic waste to liquid fuel over commercial cracking catalysts Effect of polymer to catalyst ratio/acidity content," Journal of Molecular Catalysis A: Chemical, vol. 235, no. 1-2, pp. 67-73, July 2005.

[9] X. Yang, L. Sun, J. Xiang, S. Hu, and S. Su, "Pyrolysis and dehalogenation of plastics from waste electrical and electronic equipment (WEEE): A review," Waste Management, vol. 33, no. 2, pp. 462-473, February 2013.

[10] J. F. Mastral, C. Berrueco, M. Gea, and J. Ceamanos, "Catalytic degradation of high density polyethylene over nanocrystalline HZSM-5 zeolite," Polymer Degradation and Stability, vol. 91, no. 12, pp. 3330-3338, December 2006.

[11] X. Zhang, H. Lei, G. Yadavalli, L. Zhu, Y. Wei, and Y. Liu, "Gasoline-range hydrocarbons produced from microwave-induced pyrolysis of low-density polyethylene over ZSM-5," Fuel, vol. 144, pp. 33-42, March 2015.

[12] J. Bozi and M. Blazsó, "Catalytic thermal decomposition of polyamides and polyurethanes mixed with acidic zeolites," Journal of Analytical and Applied Pyrolysis, vol. 97, pp. 189-197, September 2012.

[13] W. L. Fanchiang, and Y. C. Lin, "Catalytic fast pyrolysis of furfural over H-ZSM-5 and Zn/H-ZSM-5 catalysts," Applied Catalysis A: General, vol. 419-420, pp. 419-420, March 2012.

[14] R. A. García, D. P. Serrano, and D. Otero, "Catalytic cracking of HDPE over hybrid zeolitic-mesoporous materials," Journal of Analytical and Applied Pyrolysis, vol. 74, no. 1-2, pp. 379-386, August 2005.

[15] A. López, I. Marco, B. M. Caballero, M. F. Laresgoiti, A. Adrados, and A. Aranzabal, "Catalytic pyrolysis of plastic wastes with two different types of catalysts: ZSM-5 zeolite and Red Mud," Applied Catalysis B: Environmental, vol. 104, no. 3-4, pp. 211-219, May 2011.

[16] M. R. Jan, J. Shah, and H. Gulab, "Catalytic conversion of waste high-density polyethylene into useful hydrocarbons," Fuel, vol. 105, pp. 595-602, March 2013.

[17] K. H. Lee, "Composition of aromatic products in the catalytic degradation of the mixture of waste polystyrene and high-density polyethylene using spent FCC catalyst," Polymer Degradation and Stability, vol. 93, no. 7, pp. 1284-1289, July 2008.

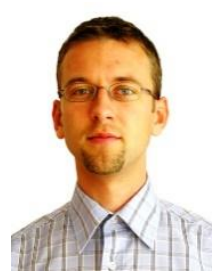

Norbert Miskolczi is an Associate Professor at MOL Department of Hydrocarbon and Coal Processing, University of Pannonia, Hungary. He has published 57 academic papers with $>450$ citations with an ' $h$ factor' of 13 (Scopus). He has been awarded research grants, and his research work has been honored by several awards. Among others he is a member of the Institution of Chemical Engineering and Hungarian Chemical 
Society. He has worked in the areas of waste to fuel processes, mechanical recycling of waste polymers and polymer composite development. He has involved also in industrial $R \& D$ projects.

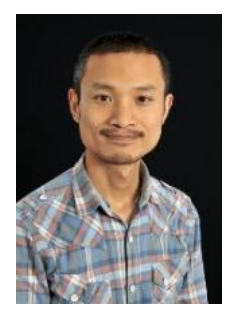

Chunfei Wu is a Lecturer in the School of Engineering at the University of Hull. He is a visiting professor of the State Key Laboratory of Coal Combustion, Huazhong University of Science and Technology. He is a principal investigator of several collaborative grants; White Rose Collaboration Fund, Royal Society International Exchange Scheme and Worldwide Universities Network. He has also been recently awarded a SUPERGEN Bioenergy small research grant $(£ 20 \mathrm{k})$ to investigate the upgrading of biomass pyrolysis oil. He is also involved in several EPSRC projects concerned with the thermo-chemical treatment of waste and biomass and EU FP7 project in waste management. He has published 63 peer reviewed

journal publications with $>650$ citations with an ' $h$ factor' of 17 (Google Scholar) in the areas of catalytic thermo-chemical conversion of biomass and wastes. He is a member of the Royal Society Chemistry and a Chartered Scientist. He has worked in the areas of converting renewable and waste resources to energy, fuel and chemicals through catalytic thermo-chemical routes for 10 years.

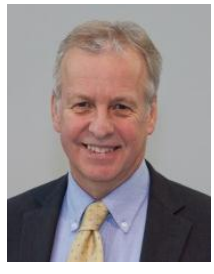

Boards.
Paul Williams is a Professor of Environmental Engineering and Director of the Doctoral Training Centre in Low Carbon Technologies at the University of Leeds, UK. He has published more than 450 academic papers with more than 12,000 citations. He has been awarded research grants, totaling over $€ 20 \mathrm{M}$ and his research work has been honored by awards from the UK Energy Institute and the Royal Society of Chemistry. He is a member of several journal Editorial 